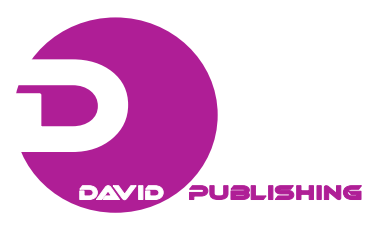

\title{
Tourist Route Model Formulation Method Considering Spatial Reproducibility
}

\author{
Hiroyuki Kawai $^{1}$ and Kayoko Yamamoto ${ }^{2}$ \\ 1. SJI Inc., Tokyo 140-0002, Japan \\ 2. Graduate School of Information Systems, National University of Electro-Communications, Tokyo 182-8585, Japan
}

\begin{abstract}
This study aims to gradually reflect information concerning tourists and to propose tourist route model formulation techniques that take spatial reproducibility into account using GIS (geographic information systems). The conclusions can be summarized into the following three points: (1) Kawagoe city in Saitama Prefecture was selected as the area targeted by this study. All types of data about Kawagoe city and tourists was collected and processed, and a tourist route model formulation method that considered spatial reproducibility using GIS was proposed, (2) 3-stage scenarios were created with the presence or absence of Kawagoe city tourist policies set as standards and this was used to develop tourist route models. It is possible to expect synergy in the encouragement of the use of sightseeing buses and the same traffic regulations as the traffic pilot program, and (3) It is considered that it is possible to apply the tourist route model formulation method proposed by this study to other tourist destinations without being limited by spatiotemporal differences or the particular issues of each tourist destinations as spatial reproducibility was confirmed.
\end{abstract}

Key words: Tourist route model, sightseeing spot, spatial reproducibility, GIS (geographic information systems), Kawagoe city.

\section{Introduction}

\subsection{Background and Purpose of Study}

There has been a recent activation in trends to review many small and large tourist attractions in Japan. The main causes of this can be considered to be various town and community planning and revitalization activities in many areas and the policies of the Japan Tourism Agency. In the background of the Visit Japan Campaign (started in 2004) which had the goal of 10 million overseas visitors to Japan, the Japan Tourism Agency had the aim of establishing international competitiveness for the development of tourist destinations in particular and supporting local authorities with diverse policies. Further, with the increase in social anxiety caused by the 2007 global financial crisis, it has been supporting the move to review the focus on short trips as cheap entertainment within Japan.

Corresponding author: Kayoko Yamamoto, $\mathrm{PhD}$, associate professor, research fields: urban planning and GIS. E-mail: k-yamamoto@is.uec.ac.jp.
As there is focus on domestic tourist destinations, if urban areas are made into tourist destinations, places that did not function as such before will develop new issues. In other words, the necessity to estimate severe changes such as unforeseen tourist numbers and types that were unimaginable before will come to the forefront. There is a demand for new policies for local authorities, because there are actual issues such as poor services of the display of information for sightseeing spots and modes of transport, and under-developed basic barrier-free facilities. In actual fact, the majority of local authorities that have tourist destinations are looking for policies that do not detract from the attraction of subtle tourist destinations such as simple scenes of days gone by and places with an historical appearance.

However, high costs are involved in accurately grasping the behavior of tourists and this is a great burden on local authorities. Further, as there are many changes in information about tourists due to the effects of time and media, it is essential to implement continuously methods that can be expected to have a 
certain amount of accuracy and researches on a suitable scale. Therefore, the consideration of tourist policies and the confirmation of their results are difficult issues for local authorities.

In order to move past the current situation as outlined above, it is necessary to link to the reduction of the burden for local authorities and to implement prompt and effective policies by conducting spatial analysis of tourist destinations using methods that are able to adapt flexibly to changes in spatiotemporal elements. In order to do this, it is essential to fully consider the diverse issues that tourist destinations have, the scale of local authorities that have tourist destinations and the type of spatial information that it is possible to collect. Accordingly, this study aims to reflect stratified information about tourists and use GIS (Geographic Information Systems) (This study used ESRI's ArcGIS Ver9.2 as its GIS application.) to propose tourist route model formulation methods considering spatial reproducibility. Even if there are tourist routes that depart from and end up in the same place, spatial information about each route should differ according to tourist gender, age and preferences, the mode of transport that they use and concomitant circumstances. Through case-by-case consideration and weighting, getting spatial information as close to the real world as possible is defined as "spatial reproducibility" in this study.

\subsection{Previous Research and the Position of This Study in Related Fields}

There are many examples of research including tourist route information in fields related to this study. Representative examples of research are a study on mathematical methods to derive optimized tourist routes in order to maximize the value of the route in response to diverse restrictions due to the attributes of tourists [1, 2], a study on methods using GIS in analysis that conducts spatial weighting [3] or a study that effectively combines these methods [4]. As this study considers the use of GIS as a solution for tourist route issues as the main point, it is affiliated with methods that use GIS.

In addition, this study differs from tourist route issues that correspond to information concerning particular individuals, and it has a connection with the research field of tourist behavior as it conducts the classification of tourists into patterns using things such as information gained from surveys from the viewpoint of spatial reproducibility. In this kind of research field, there are representative examples as a study that classifies tourist behavior into patterns through a questionnaire [5], a study that classifies tourist behavior into patterns and gives suggestions for transport plans [6], a study that looks for clues of revitalization in tourism from tourist behavior that has been classified into patterns [7, 8] and a study that estimates tourist shopping routes [9].

Furthermore, as there are many cases of the transportation environment being viewed as an issue at tourist destinations that are targeted in this study, it has an aspect of research into cost settings for the development of tourist routes. GIS is also utilized in a multi-faceted manner in this kind of research field, and there are representative examples such as a study on the usefulness of GIS in transport policy management [10], a study on GIS development that conducts walking assistance for seniors and the disabled [11], a study that estimates pedestrian traffic volume with GIS [12], and a study that combines ontology and GIS to develop a system that supports the choice of optimum tourist route for each tourist [13].

Many studies concerning tourist route issues only analyze general information as a wide range of types of tourist destination and tourists are targeted. For this reason, it is difficult to take the special characteristics of targeted tourists and the special circumstances and issues of communities into account. Meanwhile, it is hard to accurately reflect information concerning tourists in research about tourist behavior. This is because it is difficult to obtain detailed information from questionnaires which are comparatively easy to 
conduct and because it is unrealistic to use equipment such as GPS (Global Positioning System) due to issues with sample numbers. Moreover, most of the research listed above considers improvement measures but spatial reproducibility is not considered much. Consequently, through consideration of spatial reproducibility corresponding to disadvantages of research about tourist route issues and, stratified reflection of information about tourists that overcomes challenges in research about tourist behavior, the originality of this study is demonstrated in the point that it develops tourist route models using GIS.

\section{Research Methods}

\subsection{Research Framework and Methods}

First of all, Section 3 proposes methods to develop tourist route models divided into the two stages of simple and complex route models on top of demonstrating the process of the tourist route model formulation methods in this study. Section 4 collects and processes digital map data and the information from local authority surveys in the study area, and shows how these are used in the tourist route model formation process. Further, it gives an outline of opinion polls and local trials conducted independently by this study in order to collect the required data for tourist route model formation.

Based on the above, Section 5 divides tourist route models into the two stages of simple and complex route models, and uses the data collected and processed in the previous section to develop route models that go around the sightseeing spots in the study area. Furthermore, Section 6 creates scenarios introducing tourist policies in the study area and uses these to develop tourist route models. In addition, based on the results of comparison and review of tourist route models, tourist route issues are identified and tourist policies are evaluated in the study area. Finally, Section 7 gives the conclusions of the study and identifies future research challenges.

\subsection{Selection of Study Areas}

Kawagoe City in Saitama Prefecture was selected as the study area. Kawagoe City is located at around approximately $30 \mathrm{~km}$ from the center of Tokyo and has a population of approximately 343,500 . It is a popular tourist destination called "Little Edo" with around six million visitors yearly and there is a year on year increasing trend in tourists. Due to the city's geographical proximity to the center of Tokyo, commerce, industry and agriculture are stable and growing, and there is an increasing trend in total population. However, there are tourist route issues caused by narrow and complicated roads due to Kawagoe's historical background as a castle town, and these are made worse by an increase in population and tourists. The results of the Kawagoe City resident questionnaire (2009) [14] showed that over $80 \%$ of residents thought that the transportation environment in the urban center was not good, and the results of the Kawagoe City tourism questionnaire [15] showed that over $30 \%$ of tourists requested improvements in the safety of transportation.

Among the representative sightseeing spots in Kawagoe City, Fig. 1 shows the area around Toki no Kane (Time Bell Tower), and Fig. 2 shows Kashiya Yokocho (Penny Candy Alley). As shown in these photos, main tourist route roads are narrow in breadth and are winding in places. In addition, sightseeing spots that are the target for analysis are the seven most

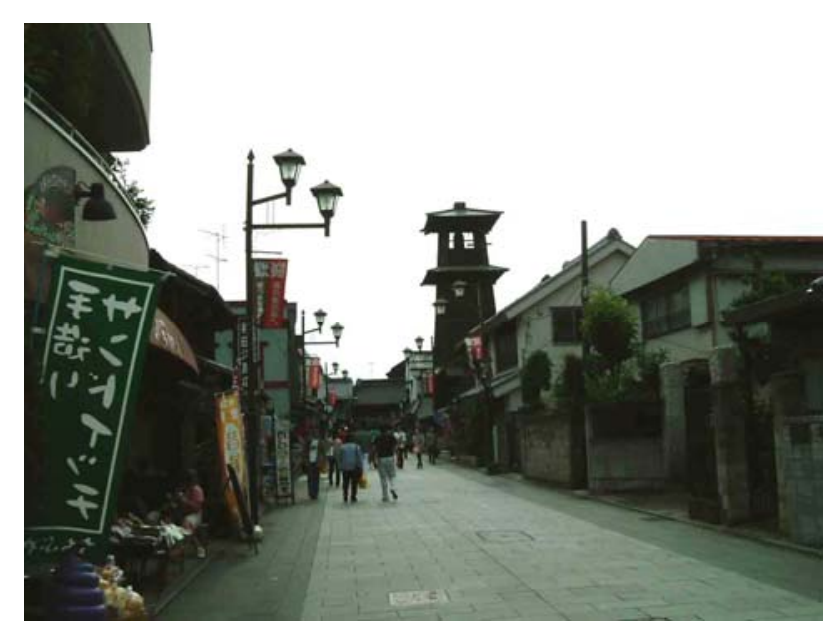

Fig. 1 Toki no Kane (June, 2010). 


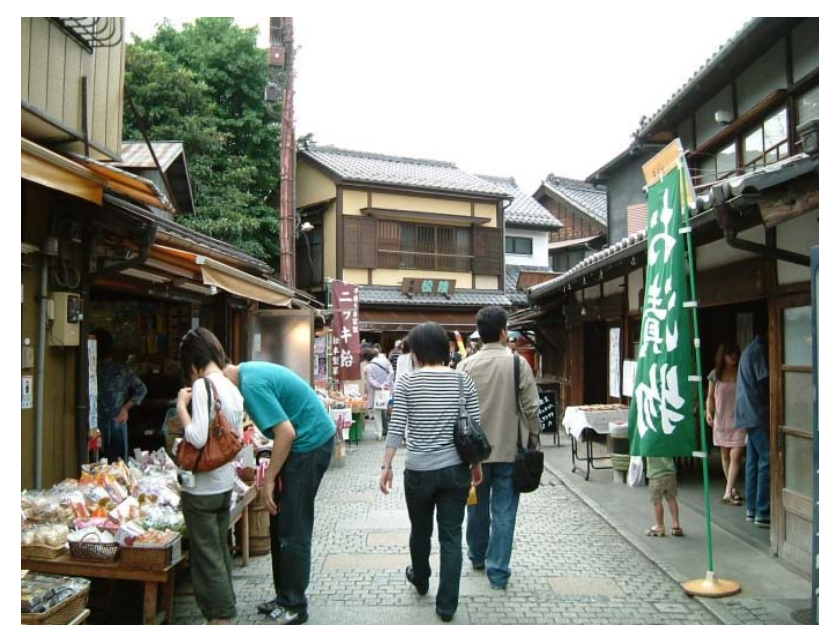

Fig. 2 Kashiya Yokocho (June, 2010).

popular sightseeing spots amongst tourists according to the Kawagoe City tourism questionnaire [15] which are: Kura no Machi (Old Kura Storehouses), Toki no Kane, Kura-zukuri Museum (Kura Storehouse Museum),Kashiya Yokocho, Kawagoe City Museum, Honmaru Goten (Feudal Palace) and Kita-in Temple. These sightseeing spots are divided into three sightseeing spot zones (Kura no Machi Zone, Kita-in Temple Zone and Museum Zone). There are two train stations (Kawagoe Station and Hon-Kawagoe Station) which are a base for tourists and two types of sightseeing buses that operate between the sightseeing spots. This study applied tourist route models developed taking the above into account, and assessed

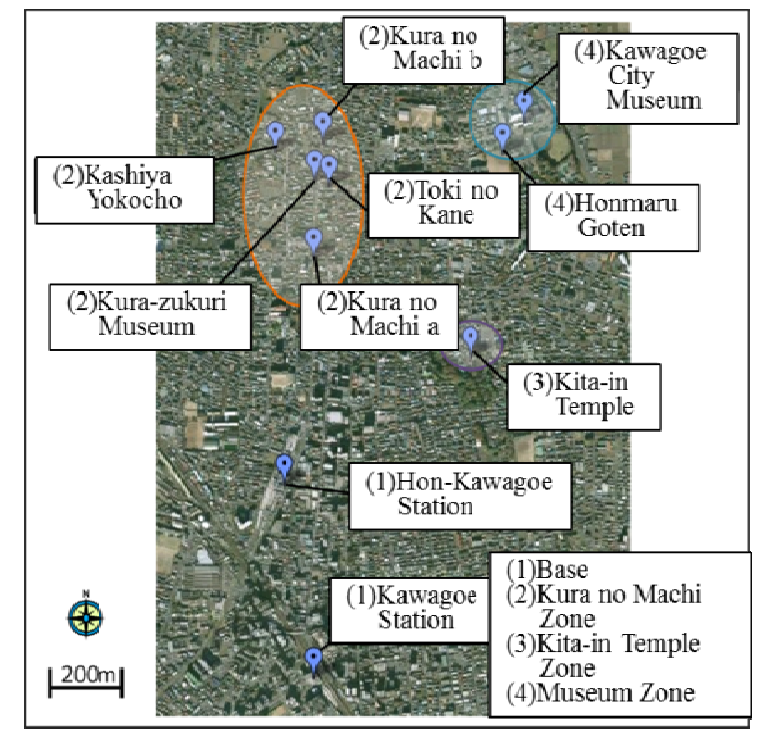

tourist policies with the aim of improving the transportation environment surrounding local residents and tourists by identifying the tourist route issues in Kawagoe City.

\section{Tourist Route Model Formulation Method}

Fig. 4 shows the tourist route model development process and tourist route models for Kawagoe City were developed following the process in this study. The details of the main part of Fig. 4 are as follows:

\subsection{Collection of Diverse Data for Kawagoe City}

Data such as information on tourist destinations, tourists, modes of transport and tourist policies as well as digital map data for roads was collected. Tourists were classified into patterns and tourist routes were estimated using the above-mentioned data;

\subsection{Creation of Database and Analysis}

First of all, GIS was used to process digital map data for roads into formations in which analysis was possible. Next, for the shortest route estimating realistic tourist routes with time as the cost, safe route cost settings estimating ideal tourist routes with degree of road congestion as the cost were made. In the case of Kawagoe City, it is considered that the ideal tourist route is the safest route that selects the

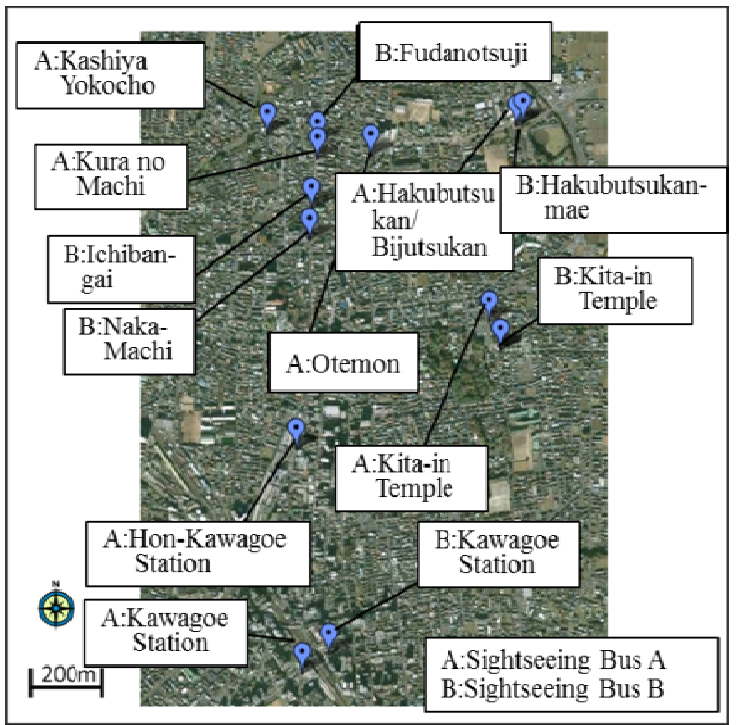

Fig. 3 Sightseeing spots that are the target for analysis and position of bases (Left) and sightseeing bus stop positions (Right), note: Created with Google Maps. 


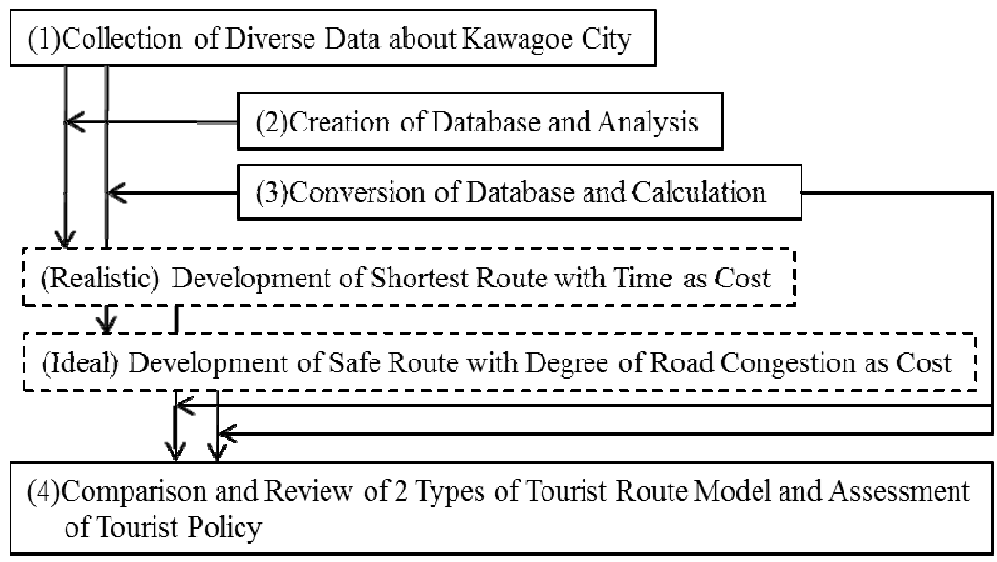

Fig. 4 Tourist route model development process.

widest roads, even if it is a roundabout way. Simple routes that show possible movement of tourists from one point to another were developed according to the above two types of cost settings;

\subsection{Conversion of Database and Calculation}

A spreadsheet program was used to identify attribute values from dbf files of all simple routes and a summary file was created. Using this summary file, complex routes were developed by combining attribute values that correspond to case-by-case consideration. In addition, weighting was conducted for the usage ratio of each complex route and tourist route models were created;

\subsection{Comparison and Review of Two Types of Tourist} Route Model and Assessment of Tourist Policies

The degree of divergence between the shortest and the safe route calculated under the same conditions was identified. Further, tourist route issues were identified and tourist policies were assessed by comparing and reviewing tourist route models according to the above-mentioned two types of routes.

\section{Overview of Data Used}

\subsection{Collection and Processing of Data Used}

This study developed tourist route models using the data below and digital map data as a base map:

4.1.1 Digital Map Data
This study used pedestrian network data from options in MAPPLE10000 digital map data from Shobunsha Publications for the transportation environment in Kawagoe City. This digital map data is optimum for the purposes of this study, because it includes attribute values for the width of each road in addition to special road network information which are not included in other digital map information such as station building structures, etc.;

4.1.2 Data relating to Kawagoe City Survey and Administrative Policies/Plans

(1) Tourism questionnaire report (survey implemented each year from 2007-2009) [15];

(2) Kawagoe City local public transportation comprehensive coordination plan (2010 decision) [16];

(3) Results of questionnaire about transport in Ichiban-gai of Kawagoe City (Traffic pilot program and survey conducted in 2009) [14].

The traffic pilot program was conducted in 2009 on vehicle regulations in the Kura no Machi Zone (Ichiban-gai) which has the most serious problem with the worsening of the traffic environment, and traffic regulations that changed two-way roads into one-way roads on weekdays and closed roads on holidays in certain time bands were implemented;

4.1.3 Data from Surveys Conducted Independently by This Study

(1) Opinion poll about sightseeing spots (November, 2010); 
(2) Local trial and opinion poll concerning the trial (October, 2010).

\subsection{Data from Surveys Conducted Independently by This Study}

As shown in the previous section, this study conducted two types of opinion polls independently to use them for weighting at the time of development of complex route models in the following section onwards. First of all, it gives an overview of an opinion poll about sightseeing spots in Table 1 and it was evident that there were overall trends such as women having a worse impression of congestion than men and people having a worse impression of congestion the older they are.

Furthermore, the local trial and the opinion poll concerning the trial aimed to grasp how tourists feel about the differences between road width and travelling distance on the shortest and the safe routes on the simple route between Kawagoe Station and Kita-in Temple developed in Section 5, and to survey the usage preferences for Kawagoe city sightseeing buses. As the outline in Table 2 demonstrates that a local trial was conducted and an opinion poll was taken immediately following it. From the results of the opinion poll, it was evident that the majority of people preferred the safe route and did not feel a difference in distance between the safe route and the shortest route. In addition, there were many people who preferred using the sightseeing bus in the 50 and over age range.

\section{Development of Route Models}

\subsection{Simple Route Models}

The procedure for the development of simple route models using GIS is demonstrated according to Fig. 5.

\subsubsection{Cost Calculation Method Using Basic} Information

In order to develop both the shortest route estimating a realistic tourist route with time as the cost and the safe route estimating an ideal tourist route with degree of road congestion as the cost in this study, these require costs were calculated from the attribute values of each route. As the realistic movement of tourists can be

Table 1 Outline of opinion poll about sightseeing spots.

\begin{tabular}{|l|l|}
\hline Target & Residents of Tokyo Metropolitan and Saitama Prefecture — Junior High School Age and Over \\
\hline $\begin{array}{l}\text { Number of } \\
\text { respondents }\end{array}$ & 326 \\
\hline Duration & 19th November - 5th December, 2010 \\
\hline Poll method & Individual interview \\
\hline $\begin{array}{l}\text { Question } \\
\text { categories }\end{array}$ & $\begin{array}{l}\text { 5-stage questions about impressions of degree of road congrestion in the areas surrounding 3 types of } \\
\text { sightseeing spots similar to those in Kawagoe such as sightseeing spots with a historical background, new } \\
\text { sightseeing spots (theme parks, etc.) and integrated sightseeing spots. }\end{array}$ \\
\hline
\end{tabular}

Table 2 Outline of local trial and the opinion poll concerning the trial.

\begin{tabular}{|c|c|}
\hline \multicolumn{2}{|l|}{ Local Trial } \\
\hline Target & 20 people who are not reside in Kawagoe City, Saitama Prefecture and who do not have local knowledge \\
\hline Date & 14th October, 2010 \\
\hline Method & $\begin{array}{l}3 \text { people guided } 20 \text { people acting as tourists on the shortest route between Kawagoe Station and Kita-in } \\
\text { Temple (road distance: } 1.7 \mathrm{~km} \text { ) and back on the safe route (road distance: } 2.4 \mathrm{~km} \text { ) }\end{array}$ \\
\hline \multicolumn{2}{|l|}{ Opinion poll } \\
\hline Target/Respondents & 20 participants in the local trial \\
\hline Date & 14th October, 2010 (directly after the implementation of the local trial) \\
\hline Poll method & Collective interview \\
\hline Question categories & $\begin{array}{l}\text { How easy it was to walk the shortest route, how easy it was to walk the safe route, comparison of the } \\
\text { shortest route and the safe route, acknowledgement of differences between the shortest route and the safe } \\
\text { route, preference between the shortest route and the safe route, preference for use of sightseeing buses }\end{array}$ \\
\hline
\end{tabular}


considered to use the short route to travel in a direct line to sightseeing spots, calculation of cost (required time to pass through each road) is fixed on the shortest route estimating a realistic tourist route. Meanwhile, as safe route costs differed depending on congestion conditions at each sightseeing spot and the area surrounding it, and pedestrian traffic environment is extremely inferior in Kawagoe City, it is essential to make cost settings that facilitate walking for tourists as much as possible. Consequently, specific costs for safe routes were calculated by dividing distances by road width and this was defined as "road width ratio";

\subsubsection{Confirmation of Location Coordinates (Fig. 3)}

As many tourists visit Kawagoe City by train and the majority of these are day-trippers, two stations (Kawagoe Station and Hon-Kawagoe Station) were designated as the two sightseeing bases. Sightseeing spots to be analyzed are the seven most popular sightseeing spots among tourists;

5.1.3 Degree of Road Congestion in the Area Surrounding Sightseeing Spots

Considering the effects of degrees of congestion on tourists when they are walking in the roads around sightseeing spots, cost calculations were conducted for roads to recreate the effects of degree of congestion on roads in the areas surrounding seven sightseeing spots. These procedures are as follows:

(1) After generating polygons showing a $400 \mathrm{~m}$ radius around each of the seven sightseeing spots using the GIS Network Analyst service area function, roads included in these polygons were searched using the spatial search function;

(2) Attribute values (road width ratio) used in the calculation of degree of road congestion included in the above-mentioned polygons fluctuated with the 5-stage scale factor of $(1.2,1.1,1.0,0.9,0.8)$. According to scale factor, if degree of road congestion increases, there is a bad effect and if costs are reduced, there is a good effect;

(3) Fluctuation of attribute values multiplies for each sightseeing spot because they duplicate due to multiple sightseeing spots.

In addition, good or bad impressions of degree of road congestion in the vicinity of sightseeing spots is considered to be greatly influenced by the gender, age and preferences of individuals, and the results of the opinion poll about sightseeing spots that this study

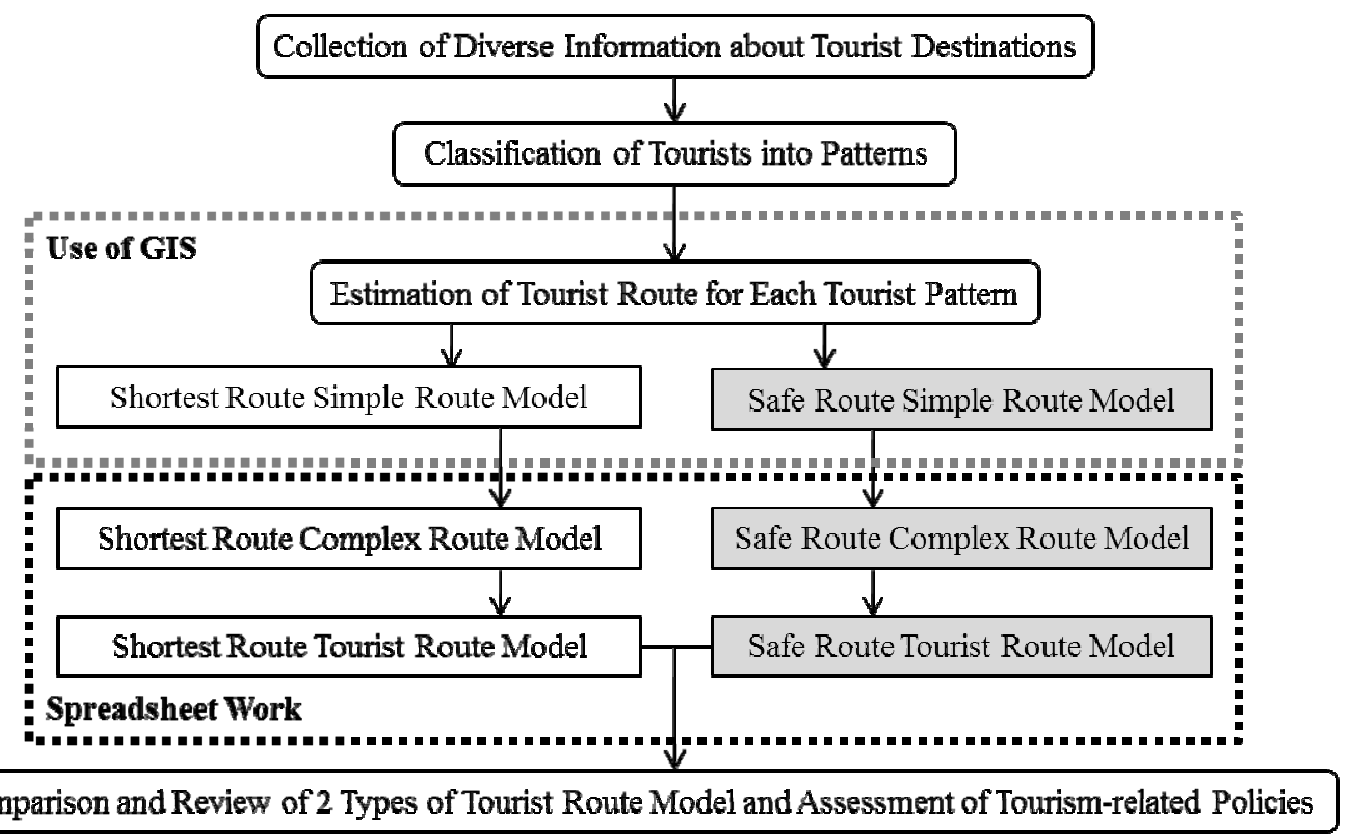

Fig. 5 Tourist route model development flow chart. 
conducted independently as shown in Section 4 (Table 1) were handled as elements of case-by-case consideration. According to research in everyday spheres by Ishihara et al. [17], the above-mentioned $400 \mathrm{~m}$ is called a general public walking sphere and is acknowledged as the everyday neighborhood and travel on foot is defined as the sphere in which it is not hard to get around on foot. For this reason, in the case of tourists travelling on foot within a sphere of $400 \mathrm{~m}$, it is assumed that there is influence from the congestion of sightseeing spots. The influence of the above-mentioned seven sightseeing spots on the 400 $\mathrm{m}$ sphere expressed on GIS is as shown in Fig. 5. As Kura no Machi is a local sightseeing spot zone, the $400 \mathrm{~m}$ sphere was calculated from the Kura no Machi zone;

\subsubsection{Confirmation of Modes of Transport}

Two types of sightseeing buses (Fig. 3) are operated for tourists in Kawagoe city and these are different from ordinary bus services. For this reason, modes of transportation in Kawagoe city were set to three types: walking, sightseeing bus A and sightseeing bus B;

\subsubsection{Confirmation of Tourist Routes}

Considering the operational routes for the two types of sightseeing bus, as shown in Table 3, the simplification of 11 pairs of points were combined to create a simple route, and the presence or absence of modes of transport for each simple route were arranged. As is clear from Table 3, sightseeing bus B cannot be used on the route used with Hon-Kawagoe Station, because sightseeing bus B does not have a bus stop at Hon-Kawagoe Station. Further, as clear differences in popularity between the three local sightseeing spot zones (Fig. 3) set by Kawagoe city were observed, tourist routes were simplified into three patterns that go round the top one to three sightseeing spots. For this reason, unnatural tourist routes that only go to sightseeing spots in the Museum Zone which has a drop-in rate of only around 20\% were excluded from the confirmation process;

5.1.6 Assumption of Traffic Regulations
A traffic pilot program with traffic regulations in tourist centers as policy was conducted in Kawagoe city. In order to analyze the effects of similar traffic regulations as these, this study conducted the recalculation of attribute values that match the details of each traffic regulation in three stages (no regulations, weekday regulations and holiday regulations). Further, in the same way, as sightseeing bus timetables differ on weekdays and holidays, it was confirmed that it is necessary to recalculate attribute values that match holiday timetables to develop simple routes for holidays after the development of weekday simple routes;

\subsubsection{Selection of Case-by-case Considerations}

Case-by-case considerations for simple routes in Kawagoe city amount to 165 through simple routes (11 types), degree of road congestion within a $400 \mathrm{~m}$ sphere of sightseeing spots (five stages) and modes of transport (three types). However, as sightseeing bus B cannot be used on routes using Hon-Kawagoe Station as shown in Table 3, the actual figure is 145 . In addition, even though Kawagoe city implemented a traffic pilot program (2009), as there was absolutely no change to the shape of tourist routes [16], it was understood that if changes were only made to attribute accumulation values, it would be possible to calculate the effects of the same kinds of traffic regulations as were used in the traffic pilot program;

\subsubsection{Selection Conditions}

Fig. 6 shows the fluctuations of simple route No. 7 on foot due to the effects of the five stages of degree of road congestion within a $400 \mathrm{~m}$ sphere of each sightseeing spot as an example of an actually developed simple route. However, a and b, c and d in Fig. 6 are routes developed in exactly the same format, but it is necessary to handle each case separately as cost of time and road width ratio change according to the influence of sightseeing spots.

\subsection{Complex Route Models}

In the same way as the previous section, this section 
Table 3 Combination of simple routes and presence or absence of modes of transport.

\begin{tabular}{|c|c|c|c|c|}
\hline \multirow{2}{*}{$\begin{array}{l}\text { Simple } \\
\text { route } \\
\text { number }\end{array}$} & \multirow[b]{2}{*}{ Route overview } & \multicolumn{3}{|c|}{ Mode of transport } \\
\hline & & Walking & $\begin{array}{l}\text { Sightseeing } \\
\text { bus A }\end{array}$ & $\begin{array}{l}\text { Sightseeing } \\
\text { bus B }\end{array}$ \\
\hline 1 & Kawagoe Station $\rightarrow$ Kita-in Temple & o & o & o \\
\hline 2 & $\begin{array}{l}\text { Kawagoe Station } \rightarrow \text { Kura no } \quad \text { Machi } \rightarrow \text { Toki no } \quad \text { Kane } \rightarrow \text { Kura-zukuri } \\
\text { Museum } \rightarrow \text { Kashiya Yokocho }\end{array}$ & ○ & o & 0 \\
\hline 3 & Hon-Kawagoe Station $\rightarrow$ Kita-in Temple & o & o & $\times$ \\
\hline 4 & $\begin{array}{l}\text { Hon-Kawagoe Station } \rightarrow \text { Kura no Machi } \rightarrow \text { Toki no Kane } \rightarrow \text { Kura-zukuri } \\
\text { Museum } \rightarrow \text { Kashiya Yokocho }\end{array}$ & ○ & O & $\times$ \\
\hline 5 & Kita-in Temple $\rightarrow$ Honmaru Goten $\rightarrow$ Kawagoe City Museum & o & o & o \\
\hline 6 & $\begin{array}{l}\text { Kawagoe City Museum } \rightarrow \text { Kashiya Yokocho } \rightarrow \text { Kura-zukuri Museum } \rightarrow \text { Toki } \\
\text { no Kane } \rightarrow \text { Kura no Machi }\end{array}$ & ○ & O & ० \\
\hline 7 & $\begin{array}{l}\text { Kita-in } \begin{array}{l}\text { Temple } \rightarrow \text { Kura no } \\
\text { Museum } \rightarrow \text { Kashiya Yokocho }\end{array} \\
\text { Kachi } \rightarrow \text { Toki }\end{array}$ & 0 & ○ & ० \\
\hline 8 & Kura no machi $\rightarrow$ Kawagoe Station & o & o & o \\
\hline 9 & Kura no machi $\rightarrow$ Hon-Kawagoe Station & o & o & $x$ \\
\hline 10 & Kashiya Yokocho $\rightarrow$ Kawagoe Station & ० & ० & ० \\
\hline 11 & Kashiya Yokocho $\rightarrow$ Hon-kawagoe Station & o & o & $x$ \\
\hline
\end{tabular}

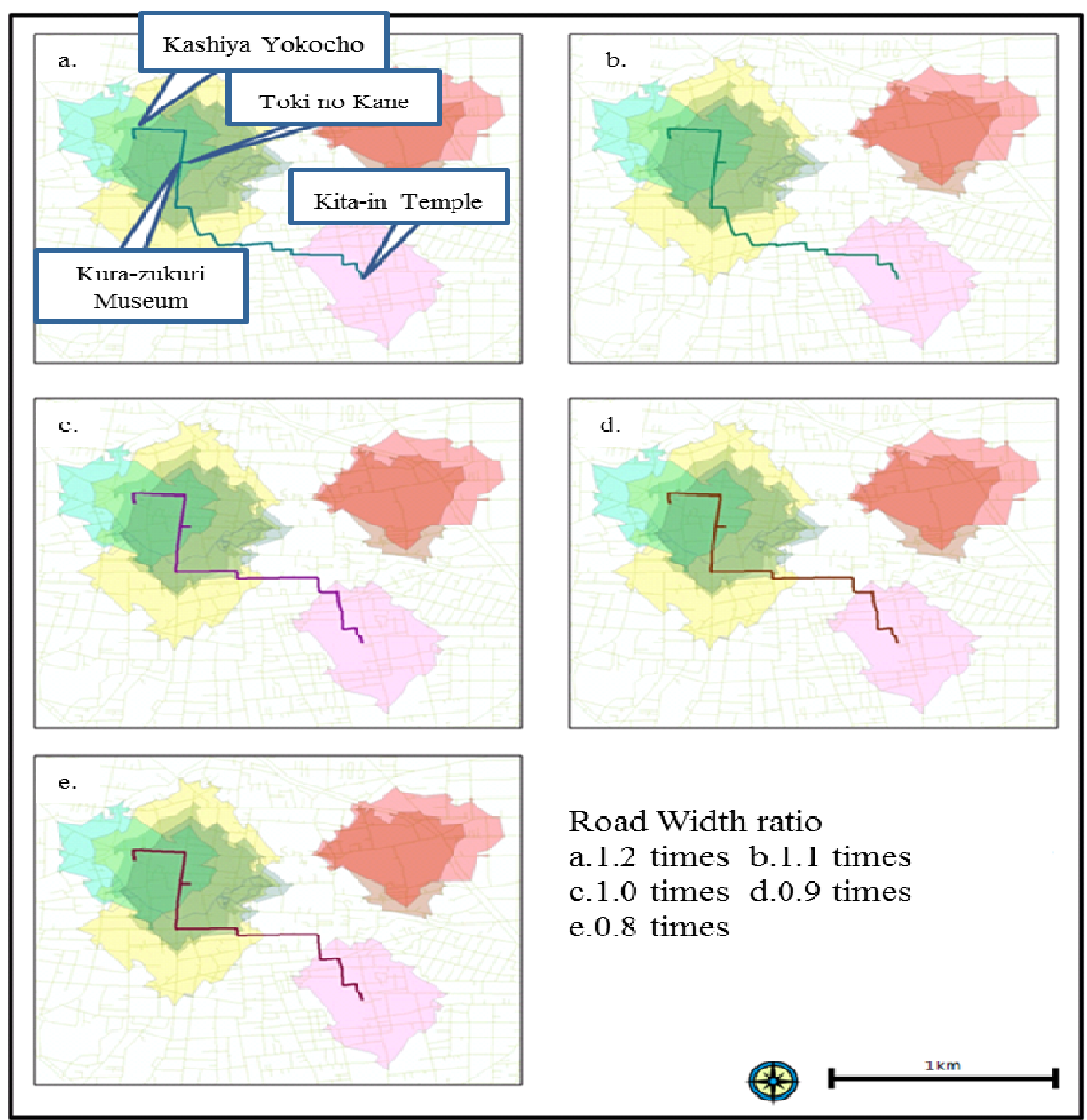

Fig. 6 Example of simple route development (simple route No. 7 walking), note: The coloured parts of the map show the sphere of effect of each sightseeing spot (400 $\mathrm{m}$ sphere). 
demonstrated the procedure in order to develop complex route models using spreadsheet software according to Fig. 5 .

\subsubsection{Creation of Data}

First of all, the required attribute values were identified and two types of list files for the shortest route and the safe route on weekdays were created. Next, the applicable simple route travelling time was recalculated referring to holiday timetables for the two types of sightseeing buses and the same list file as above was created for holidays;

5.2.2 Case-by-case Consideration for Route Composition

Case-by-case consideration was conducted as shown in Table 4. Each sightseeing spot is treated in conjunction with the other spots in the zone and the number of sightseeing spots visited is substituted with the number of sightseeing spot zones;

\subsubsection{Comparison of Simple Routes}

Attribute values that are calculated according to case-by-case considerations are basically selected for each simple route in case-by-case considerations. However, in case-by-case considerations for mode of transport, there is a comparison of numerical values for each attribute value and efficient modes of transport with the shortest travelling times are chosen;

\subsubsection{Confirmation of Travel Conditions}

Departure is from Kawagoe Station or Hon-Kawagoe Station, all sightseeing spots are visited according to case-by-case consideration and there is a check on whether all spots have been visited. In the development of complex routes, the attribute values of two simple routes that are the least frequented and of four simple routes that are the most frequented were combined. The travelling speed for tourists was divided into three age ranges for tourists as shown in Table 4 and, based on tourist age ratio according to the results of the Kawagoe City tourism questionnaire [15], these were set as a speed of $4 \mathrm{~km}$ per hour (ages 10-29), $3 \mathrm{~km}$ per hour (ages 30-59) and $2 \mathrm{~km}$ per hour (age 60 and over). Fig. 7 shows an example of a complex route developed by combing the four simple routes and sets degree of road congestion within a 400 $\mathrm{m}$ sphere of each sightseeing spot at 1.2 in the case of everyone travelling on foot;

\subsubsection{Complex Route Case-by-case Considerations}

As scenarios with added stratified information are created in order to review spatial reproducibility, as case-by-case consideration numbers in every scenario, in other words, tourist route model numbers differ. This is detailed in Section 6;

\subsubsection{Weighting Complex Routes}

In order to create scenarios with added stratified information as mentioned above, developed tourist route model numbers differ in every scenario and weighting calculations also differ in all scenarios. The details of weighting are in Section 6.

\section{Development of Tourist Route Models Used in Scenarios and Assessment of Tourist Policy}

\subsection{Overview of Scenarios}

\subsubsection{Tourist Policy Considered in Scenarios}

This section creates scenarios for the introduction of Kawagoe city tourist policy and develops tourist route models using this. Specifically, 3-stage scenarios set with the presence or absence of three tourist policies as standards are created and tourist route models using these are developed. Each stage of tourist policies was set as follows.

(1) Tourism questionnaire

As tourism questionnaires were conducted at a number of local authorities other than Kawagoe city as a basis for tourist policy and this was considered as the more general information, it was positioned as the first stage;

(2) Sightseeing buses

This is one of the tourist policies in order to ease Kawagoe city tourist route issues. However, when compared to the next stage of the traffic pilot program, as two types of sightseeing buses were already in operation, it was positioned as the second stage; 
Table 4 Case-by-case consideration for the development of complex route models.

\begin{tabular}{|l|c|}
\hline Case statement conditions & Case statement number \\
\hline Start and end position (Kawagoe Station and Hon-kawagoe Station) & 2 \\
\hline Number of sightseeing spot visits (number of sightseeing spot zones) & 3 \\
\hline 5-stage degree of road congestion within 400 m of each sightseeing spot (1.2, 1.1,1.0,0.9,0.8) & 5 \\
\hline Weekdays/Holidays & 2 \\
\hline Tourist travelling speed (Divided into 3 age ranges) & 3 \\
\hline Tourist use of modes of transport (Walking 2 types of sightseeing bus) & 3 \\
\hline
\end{tabular}

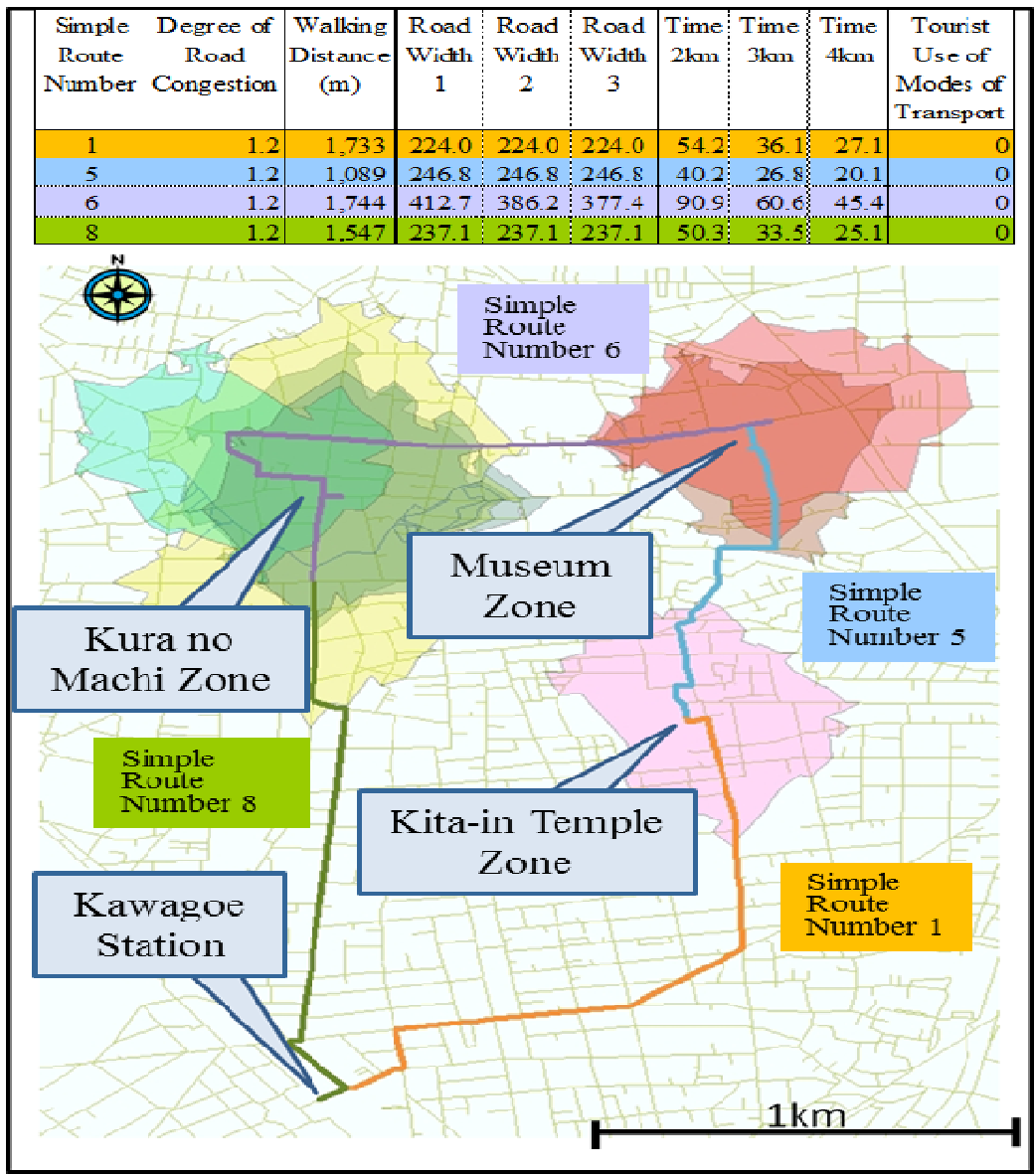

Fig. 7 Example of complex routes.

Note: Colours in the table and the map correspond for each route and coloured areas show the sphere of influence of each sightseeing spot (400 m sphere).

Simple route number: Table 3.

Degree of road congestion: 5-stage degree of road congestion within $400 \mathrm{~m}$ of each sightseeing spot.

Road Width1: Normal road width ratio.

Road Width 2: Road width ratio for weekday traffic regulations the same as those in the traffic pilot program.

Road Width 3: Road width ratio for holiday traffic regulations the same as those in the traffic pilot program.

Time $2 \mathrm{~km}$, Time $3 \mathrm{~km}$, Time $4 \mathrm{~km}$ : Time required for travel at $2 \mathrm{~km}$ per hour, $3 \mathrm{~km}$ per hour, $4 \mathrm{~km}$ per hour (in minutes). Mode of transport number: Tourist use of modes of transport ( 0 : in the case of all travel being on foot).

(3) The same traffic regulations as the traffic pilot program
This is the most proactive tourism-related policy in order to solve Kawagoe City tourist route issues. 
However, this is no more than an experimental pilot program at present and it was positioned as the third stage after the development of the actual tourist route models taking the sightseeing buses into account in the previous stage so that the route models which are a prerequisite to this traffic pilot program become virtual. However, even though Kawagoe City implemented a traffic pilot program (2009), as there was absolutely no change to the shape of tourist routes [16], there was no need to develop new simple route models and it was possible to calculate effects of traffic regulations that are the same as the traffic pilot program only with calculations of attribute values.

6.1.2 Reflection of Stratified Spatial Information in Each Scenario

The details of each scenario are as follows and tourist route models are developed based on analysis of these scenarios.

(1) Scenario A according to geographical information only

This is a scenario that supposes that Kawagoe city does not implement either opinion polls about tourism or tourist policies and conducts analysis only with the minimum amount of information. Train station as start and end points and sightseeing spot position coordinates only are added in basic digital map data. As route weighting uses only tourist gender and age ratio with weighted average discovered from the results of the Kawagoe City tourism questionnaire [15] showed in Section 4, train station usage ratio and sightseeing spot drop-in ratio are equal;

(2) Scenario B taking tourism questionnaire results into account

This takes Scenario A and the results of the Kawagoe City tourism questionnaire [15] and the opinion poll concerning local trial (Table 2) into account. However, survey results concerning sightseeing buses that are a Kawagoe City tourist policy are not included. Through the creation of scenarios that take the comprehension of actual sightseeing spot based on the above two types of survey into account and the comparison with scenario A, the importance of the above-mentioned tourism questionnaire was confirmed. As information has been weighted only according to train station usage ratio and sightseeing spot drop-in ratio in addition to the tourist gender and age ratio in scenario $\mathrm{A}$, case-by-case consideration numbers are the same numbers as in scenario A. However, tourist route models are developed based on the results of the Kawagoe City tourism questionnaire [15];

(3) Scenario C considering the use of sightseeing buses

Scenario $\mathrm{C}$ is the most highly accurate analysis of all data with the use of sightseeing buses included in addition to Scenario B. As it considers the use of sightseeing buses, it is different from scenario B. By the fact that sightseeing bus timetables differ on weekdays and holidays and by reflecting required tourist travel speed calculated from the results of the Kawagoe City tourism questionnaire [15] in order to grasp switches between walking and sightseeing buses, case-by-case consideration numbers are 540 when compared to scenario B - a huge increase. Therefore, it is possible to confirm the effects of sightseeing buses through a comparison with scenario B.

\subsection{Development of Tourist Route Models Using Scenarios}

Below is a detailed explanation of an outline of tourist route model development using each scenario. Additionally, Table 5 organizes case-by-case consideration and weighting showing spatial reproducibility for each scenario in a list. Scenarios B and C develop three years' worth of tourist route models as the results of the Kawagoe City tourism questionnaire [15] are used:

(1) Scenario A according to geographical information only

Scenario A develops a total of 30 tourist route models from the influence of six types of complex routes and five stages of sightseeing spots. Weighting 
elements for complex routes were only weighted averages of gender and age in the opinion poll about sightseeing spots (Table 1). Further, the usage ratio of six types of complex routes were all set as equal (coefficient $16.6 \%=1 / 6$ ). Further, as this scenario assumes that there are no past tourism questionnaires, tourist gender and age ratios, train station usage ratios and sightseeing spot drop-in ratios have not fluctuated in the past three years;

(2) Scenario B taking tourism questionnaire results into account

Scenario B develops a total of 30 tourist route models from the influence of six types of complex routes and five stages of sightseeing spots in the same way as Scenario A. However, weighting elements for complex routes correspond to weighted averages for gender and age in the opinion poll about sightseeing spots (Table 1). When corresponding these opinion poll results to the results of the Kawagoe city tourism questionnaire [15], respondents for whom gender or age are unknown for questionnaire were not analysed and were removed from the sample numbers. Moreover, in the same way as the six complex routes, tourists other than those who were targeted for analysis in the results of the Kawagoe city tourism questionnaire [15] are removed from the sample numbers, and weighting is based on usage ratio for each train station and drop-in ratio for each sightseeing spot. In addition, if multiple sightseeing spots are included in one zone, it is standard that the order of popularity of each sightseeing spot zone is the most popular sightseeing spot in each zone;

(3) Scenario C considering the use of sightseeing buses

Scenario $\mathrm{C}$ is the scenario with the highest spatial reproducibility as a further addition of the use of sightseeing buses to scenario B and a total of 540 tourist route models were developed. First of all, weekday and holiday routes were separated and weighting was conducted for rough weekday (245 days) and holiday (120 days) ratios. In addition, tourist travelling speed was set at $4 \mathrm{~km}$ per hour (ages 10-29), $3 \mathrm{~km}$ per hour (ages 30-59) and $2 \mathrm{~km}$ per hour (age 60 and over) as shown in Section 5-2. Further, sightseeing bus usage ratio is calculated by the tourist age and gender ratios discovered from the results of the Kawagoe city tourism questionnaire [15] corresponding to results for sightseeing bus usage preferences in the opinion poll concerning the local trial (Table 2).

\subsection{Comparison and Review of Tourist Route Models and Assessment of Tourist Policies}

Table 6 shows the degree of divergence in each scenario of the shortest route with time as cost and the safe route with road width ratio that expresses degree of road congestion as cost. Further, Table 6 also shows normal average road width and average road width at the time of the traffic pilot program in order to grasp the effects of the same traffic regulations as those used during the traffic pilot program.

It was possible to confirm divergence in all scenarios in a comparison of the shortest routes and the safe routes. All scenarios had an increase of over $10 \%$ in travelling times and around $10 \%$ in walking distance. However, as there was an increase in average road width of over $30 \%$, it can be said that it is possible to improve the transportation environment for tourist destinations in Kawagoe city by following these scenarios. Further, due to this, it was also evident that tourists actively choose narrow roads and it can be considered that this links to the decline of the transportation environment surrounding local residents and tourists. For that reason, it can be said that it is possible to improve the tourist route transportation environment by leading tourists to safe routes using wide roads which are deliberately the long way round. Further, when normal average road width and average road width at the time of the traffic pilot program in Table 6 are compared, it was also discovered that there was an increase of over $5 \%$ in the increase ratio of average road width due to the 
implementation of the same traffic regulations as the traffic pilot program.

When scenarios $\mathrm{B}$ and $\mathrm{C}$ are compared, it is understood that tourist travelling time and walking distance are both greatly reduced over all three years due to an increase in transportation methods such as sightseeing buses in scenario $C$. In addition, due to the fact that there was also an increase in road width at the time of the traffic pilot program, it is understood that it is possible to expect synergy in the encouragement of the use of sightseeing buses and the same traffic regulations as the traffic pilot program. However, if traffic volume increases through the use of sightseeing buses, it is necessary to fully consider this in actual traffic regulations, as it is possible that there may be an adverse effect on tourists and local residents who walk.

As shown above, it was possible to show the effects of stratified reflection of spatial information (spatial reproducibility) which is the most remarkable feature of tourist route models proposed in this study by using scenarios with added information in three stages. For this reason, it can be considered that the methods

Table 5 List of scenario case-by-case consideration and weighting.

\begin{tabular}{|c|c|c|c|c|c|c|c|c|c|c|c|c|}
\hline Scenario & Year & \multicolumn{2}{|l|}{ Complex Route } & $\begin{array}{r}\text { 5-stage De } \\
\text { Congestion v } \\
\text { Each Sigh } \\
\end{array}$ & $\begin{array}{l}\mathrm{oad} \\
\mathrm{m} \text { of } \\
\text { ot }\end{array}$ & \multicolumn{2}{|c|}{$\begin{array}{l}\text { Weekdays/ } \\
\text { Holidays }\end{array}$} & \multicolumn{2}{|c|}{$\begin{array}{c}\text { Tourist } \\
\text { Travelling } \\
\text { Speed }\end{array}$} & \multicolumn{2}{|c|}{$\begin{array}{c}\text { Tourist Use of Modes of } \\
\text { Transport }\end{array}$} & $\begin{array}{l}\text { Case Statement } \\
\text { Number }\end{array}$ \\
\hline \multirow{6}{*}{ A } & \multirow{6}{*}{$\begin{array}{c}2007- \\
2009\end{array}$} & Kawagoe Station (1) & $16.7 \%$ & 0.8 & $15.9 \%$ & & & & & & & \multirow{6}{*}{30} \\
\hline & & Kawagoe Station (2) & $16.7 \%$ & 0.9 & $18.4 \%$ & & & & & & & \\
\hline & & Kawagoe Station (3) & $16.7 \%$ & 1.0 & $22.2 \%$ & & & & & & & \\
\hline & & Hon-Kawagoe Station (1) & $16.7 \%$ & 1.1 & $22.8 \%$ & & & & & & & \\
\hline & & Hon-Kawagoe Station (2) & $16.7 \%$ & 1.2 & $20.8 \%$ & & & & & & & \\
\hline & & Hon-Kawagoe Station (3) & $16.7 \%$ & & & & & & & & & \\
\hline \multirow{6}{*}{ B } & \multirow{6}{*}{2007} & Kawagoe Station (1) & $24.2 \%$ & 0.8 & $13.4 \%$ & & & & & & & \multirow{6}{*}{30} \\
\hline & & Kawagoe Station (2) & $30.9 \%$ & 0.9 & $16.8 \%$ & & & & & & & \\
\hline & & Kawagoe Station (3) & $17.7 \%$ & 1.0 & $21.9 \%$ & & & & & & & \\
\hline & & Hon-Kawagoe Station (1) & $9.1 \%$ & 1.1 & $24.2 \%$ & & & & & & & \\
\hline & & Hon-Kawagoe Station (2) & $11.6 \%$ & 1.2 & $23.8 \%$ & & & & & & & \\
\hline & & Hon-Kawagoe Station (3) & $6.5 \%$ & & & & & & & & & \\
\hline \multirow{6}{*}{ C } & \multirow{6}{*}{2007} & Kawagoe Station (1) & $24.2 \%$ & 0.8 & $13.4 \%$ & \multirow{3}{*}{ Weekdays } & \multirow{3}{*}{$67.1 \%$} & $2 \mathrm{~km} / \mathrm{h}$ & $33.8 \%$ & Walkig & $13.7 \%$ & \multirow{6}{*}{540} \\
\hline & & Kawagoe Station (2) & $30.9 \%$ & 0.9 & $16.8 \%$ & & & $2 \mathrm{~km} / \mathrm{n}$ & $35.0 \%$ & WalkIg & $15.1 \%$ & \\
\hline & & Kawagoe Station (3) & $17.7 \%$ & 1.0 & $21.9 \%$ & & & $3 \mathrm{~km} / \mathrm{h}$ & $533 \%$ & Effective Modes of & $53.4 \%$ & \\
\hline & & Hon-Kawagoe Station (1) & $9.1 \%$ & 1.1 & $24.2 \%$ & \multirow{3}{*}{ Holidays } & \multirow{3}{*}{$32.9 \%$} & 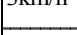 & $35.5 \%$ & Transport & 33.470 & \\
\hline & & Hon-Kawagoe Station (2) & $11.6 \%$ & 1.2 & $23.8 \%$ & & & $4 \mathrm{~km} / \mathrm{h}$ & $12.9 \%$ & Use of Sightseeing & $32.9 \%$ & \\
\hline & & Hon-Kawagoe Station (3) & $6.5 \%$ & & & & & $4 \mathrm{Km} / \mathrm{n}$ & $12.9 \%$ & Buses & $32.9 \%$ & \\
\hline \multirow{6}{*}{ B } & \multirow{6}{*}{2008} & Kawagoe Station (1) & $24.1 \%$ & 0.8 & $13.0 \%$ & & & & & & & \multirow{6}{*}{30} \\
\hline & & Kawagoe Station (2) & $36.7 \%$ & 0.9 & $16.8 \%$ & & & & & & & \\
\hline & & Kawagoe Station (3) & $11.6 \%$ & 1.0 & $21.6 \%$ & & & & & & & \\
\hline & & Hon-Kawagoe Station (1) & $9.2 \%$ & 1.1 & $24.4 \%$ & & & & & & & \\
\hline & & Hon-Kawagoe Station (2) & $14.0 \%$ & 1.2 & $24.2 \%$ & & & & & & & \\
\hline & & Hon-Kawagoe Station (3) & $4.4 \%$ & & & & & & & & & \\
\hline \multirow{6}{*}{ C } & & Kawagoe Station (1) & $24.1 \%$ & 0.8 & $13.0 \%$ & & & $2 \mathrm{~km} / \mathrm{h}$ & $37.8 \%$ & Walkig & $12.4 \%$ & \\
\hline & & Kawagoe Station (2) & $36.7 \%$ & 0.9 & $16.8 \%$ & Weekdays & $67.1 \%$ & $2 \mathrm{~km} / \mathrm{n}$ & $31.0 \%$ & WalkIg & $12.4 \%$ & \\
\hline & 2008 & Kawagoe Station (3) & $11.6 \%$ & 1.0 & $21.6 \%$ & & & $3 \mathrm{~km} / \mathrm{h}$ & $501 \%$ & Effective Modes of & $54.9 \%$ & 540 \\
\hline & 2000 & Hon-Kawagoe Station (1) & $9.2 \%$ & 1.1 & $24.4 \%$ & & & | & 30.170 & Transport & 34.970 & 340 \\
\hline & & Hon-Kawagoe Station (2) & $14.0 \%$ & 1.2 & $24.2 \%$ & Holidays & $32.9 \%$ & & & Use of Sightseeing & & \\
\hline & & Hon-Kawagoe Station (3) & $4.4 \%$ & & & & & $4 \mathrm{~km} / \mathrm{h}$ & $12.1 \%$ & Buses & $32.7 \%$ & \\
\hline & & Kawagoe Station (1) & $28.0 \%$ & 0.8 & $12.3 \%$ & & & & & & & \\
\hline & & Kawagoe Station (2) & $37.0 \%$ & 0.9 & $16.5 \%$ & & & & & & & \\
\hline B & 2009 & Kawagoe Station (3) & $6.7 \%$ & 1.0 & $21.7 \%$ & & & & & & & 30 \\
\hline & & Hon-Kawagoe Station (1) & $11.0 \%$ & 1.1 & $24.3 \%$ & & & & & & & \\
\hline & & Hon-Kawagoe Station (2) & $14.6 \%$ & 1.2 & $25.3 \%$ & & & & & & & \\
\hline & & Hon-Kawagoe Station (3) & $2.7 \%$ & & & & & & & & & \\
\hline & & Kawagoe Station (1) & $28.0 \%$ & 0.8 & $12.3 \%$ & & & $2 \mathrm{~km} / \mathrm{h}$ & $43.9 \%$ & Walkig & $9.4 \%$ & \\
\hline & & Kawagoe Station (2) & $37.0 \%$ & 0.9 & $16.5 \%$ & Weekdays & $67.1 \%$ & $2 \mathrm{~K} 111 / 11$ & 45.570 & & 5.470 & \\
\hline C & 2009 & Kawagoe Station (3) & $6.7 \%$ & 1.0 & $21.7 \%$ & & & $3 \mathrm{~km} / \mathrm{h}$ & $45.7 \%$ & Effective Modes of & & 540 \\
\hline C & 2009 & Hon-Kawagoe Station (1) & $11.0 \%$ & 1.1 & $24.3 \%$ & & & $3 \mathrm{Km} / \mathrm{h}$ & $45.1 \%$ & Transport & $51.1 \%$ & 540 \\
\hline & & Hon-Kawagoe Station (2) & $14.6 \%$ & 1.2 & $25.3 \%$ & Holidays & $32.9 \%$ & $4 \mathrm{~km} / \mathrm{h}$ & $10.4 \%$ & Use of Sightseeing & $3.5 \%$ & \\
\hline & & Hon-Kawagoe Station (3) & $2.7 \%$ & & & & & | & 10.470 & Buses & 55.570 & \\
\hline
\end{tabular}

Note: Complex routes: Kawagoe Station (1), (2) and (3) are routes that start at Kawagoe Station and Hon-Kawagoe Station (1), (2) and (3) are routes that start at Kawagoe Station.

Efficient modes of transport show the choice of the shortest travelling time in mode of transport case-by-case consideration. 
Table 6 List of scenario case-by-case consideration and weighting.

\begin{tabular}{|c|c|c|c|c|c|c|c|c|c|c|}
\hline \multirow[t]{2}{*}{ Scenario } & \multirow[t]{2}{*}{ Year } & \multirow[t]{2}{*}{ Route } & \multicolumn{2}{|c|}{ Travelling Time } & \multicolumn{2}{|c|}{ Walking Distance } & \multicolumn{2}{|c|}{$\begin{array}{c}\text { Average Road Width at } \\
\text { Normal Times }\end{array}$} & \multicolumn{2}{|c|}{$\begin{array}{c}\text { Average Road Width at } \\
\text { the Time of Traffic Pilot } \\
\text { Program } \\
\end{array}$} \\
\hline & & & Time (mins) & $\begin{array}{l}\text { Increase } \\
\text { Ratio(\%) }\end{array}$ & $\begin{array}{c}\text { Distance } \\
(\mathrm{m})\end{array}$ & $\begin{array}{l}\text { Increase } \\
\text { Ratio(\%) }\end{array}$ & \begin{tabular}{|c|} 
Road Width \\
$(\mathrm{m})$
\end{tabular} & $\begin{array}{l}\text { Increase } \\
\text { Ratio(\%) }\end{array}$ & $\begin{array}{c}\text { Road Width } \\
\text { (m) }\end{array}$ & $\begin{array}{l}\text { Increase } \\
\text { Ratio(\%) }\end{array}$ \\
\hline \multirow[b]{2}{*}{ A } & 2007 & Shortest Route & 101.9 & \multirow{2}{*}{14.1} & $4,720.1$ & \multirow{2}{*}{11.2} & 7.1 & \multirow[b]{2}{*}{39.9} & 7.3 & \multirow{2}{*}{47.9} \\
\hline & 2009 & \begin{tabular}{|l|} 
Safe Route \\
\end{tabular} & 116.3 & & $5,247.5$ & & 10.0 & & 10.8 & \\
\hline \multirow{6}{*}{ B } & \multirow{2}{*}{2007} & Shortest Route & 114.4 & \multirow{2}{*}{19.2} & $5,175.0$ & \multirow{2}{*}{13.1} & 7.1 & \multirow{2}{*}{39.7} & 7.4 & \multirow{2}{*}{45.9} \\
\hline & & Safe Route & 136.3 & & $5,854.3$ & & 10.0 & & 10.8 & \\
\hline & \multirow{2}{*}{2008} & Shortest Route & 111.9 & \multirow{2}{*}{17.5} & $4,969.7$ & \multirow[b]{2}{*}{11.7} & 7.1 & \multirow[b]{2}{*}{40.9} & 7.3 & \multirow{2}{*}{47.9} \\
\hline & & Safe Route & 131.5 & & $5,549.4$ & & 10.0 & & 10.8 & \\
\hline & \multirow{2}{*}{2009} & Shortest Route & 108.0 & \multirow{2}{*}{16.3} & $4,683.8$ & \multirow{2}{*}{10.2} & 7.0 & \multirow{2}{*}{42.2} & 7.3 & \multirow{2}{*}{49.3} \\
\hline & & Safe Route & 125.6 & & $5,160.8$ & & 10.0 & & 10.9 & \\
\hline \multirow{6}{*}{$\mathrm{C}$} & \multirow{2}{*}{2007} & Shortest Route & 77.5 & \multirow{2}{*}{9.1} & $2,266.1$ & \multirow{2}{*}{8.6} & 6.9 & \multirow{2}{*}{33.9} & 7.3 & \multirow{2}{*}{39.4} \\
\hline & & Safe Route & 84.6 & & $2,461.6$ & & 9.3 & & 10.2 & \\
\hline & \multirow{2}{*}{2008} & Shortest Route & 75.0 & \multirow{2}{*}{9.4} & $2,106.2$ & 95 & 6.9 & 35.9 & 7.3 & 415 \\
\hline & & Safe Route & 82.0 & & $2,306.6$ & (.) & 9.4 & | & 10.4 & (71. \\
\hline & 2009 & Shortest Route & 70.7 & 10.1 & $1,886.9$ & 11.3 & 7.0 & 36.8 & 7.4 & 425 \\
\hline & & Safe Route & 77.8 & & $2,100.4$ & & 9.5 & & 10.5 & 42.3 \\
\hline
\end{tabular}

Note: Increase ratio shows safe distance increase ratio compared to shortest distance.

proposed in this study are not limited to specific tourist destinations and it is possible to apply this to many tourist destinations.

\section{Conclusions and Future Research Challenges}

The conclusions of this study can be summarized in the following three points:

(1) Kawagoe city in Saitama Prefecture which has severe tourist route issues that come from the increase in population and tourists was selected as the area targeted by this study. All types of data about Kawagoe city and tourists was collected and processed, and a tourist route model formulation method that considered spatial reproducibility using GIS was proposed;

(2) Three-stage scenarios were created with the presence or absence of Kawagoe city tourist policies set as standards and this was used to develop tourist route models. It is possible to expect synergy in the encouragement of the use of sightseeing buses and the same traffic regulations as the traffic pilot program. However, if traffic volume increases through the use of sightseeing buses, it is necessary to fully consider this in actual traffic regulations as it is possible that there may be an adverse effect on tourists and local residents who walk;

(3) From the results of a comparison and review of tourist route models, it is considered that it is possible to apply the tourist route model formulation method proposed by this study to other tourist destinations without being limited by spatiotemporal differences or the particular issues of each tourist destinations as spatial reproducibility was confirmed.

Future research challenges are to propose an even more accurate tourist route model formulation method through the incorporation of information about the lives of local residents who live in the vicinity of tourist destinations, the reproduction of the mutual effects of tourists and to conduct further trials on opinion polls on local trials.

\section{Acknowledgments}

We would like to thank the cooperators of the opinion polls and local trial conducted independently by this study.

\section{References}

[1] A. Tamaki, S. Awaguni and M. Nakamura, Multi-purpose Optimum Route Issues and Solutions with MOGA, The Institute of Electronics, Information and Communication Engineers Technical Research Report, 2007, pp. 37-41. (in Japanese)

[2] J. Yuan, A. M. Morrison, L. A. Cai and S. Linton, A model of wine tourist behavior: A festival approach, International Journal of Tourism Research 10 (3) (2008) 207-219.

[3] I. Tanaka, S. Ueda, K. Sugimoto and T. Yoshikawa, Stratified Travel Assessment Method for Tourist Destinations and Facilities Using GIS, Architectural 
Institute of Japan Collection of Lectures (F-1), 2007, pp. 827-828. (in Japanese)

[4] M. Inagaki, S. Endo, K. Yamada, A. Taima and Y. Akamine, On-demand Bus Route Search through Potential Method utilizing GIS data, Intelligent Systems/Symposium Collection of Lectures and Reports, 2006, pp. 125-128. (in Japanese)

[5] S. Tanaka, Y. Kasuhara and S. Wada, Opinion analysis of little kyoto seen from the behaviour of tourists with Hida Takayama as an example, in: Japan Society of Civil Engineering 57th Annual Lecture Meeting Speech Outline Collection, 2002, pp. 321-322. (in Japanese)

[6] A. Lew and B. McKercher, Modelling tourist movements: A local destination analysis, Annals of Tourism Research 33 (2) (2006) 403-423.

[7] Z. Mottiara, Holiday home owners: A route to sustainable tourism development - An economic analysis of tourist expenditure data, Journal of Sustainable Tourism 14 (6) (2006) 582-599.

[8] S. Wada and T. Ikeda, The Revitalization of Tourism as Seen from classifying Tourist Travel Routes into Patterns, Architectural Institute of Japan Collection of Lecture (F-1), 2007, pp. 919-920. (in Japanese)

[9] A. D. A. M. Kemperman, A. W. J. Borgers and H. J. P. Timmermans, Tourist shopping behavior in a historic downtown area, Tourism Management 30 (2) (2009) 208-218.

[10] H. Fujimoto, The Effectiveness of Traffic Policy
Management utilizing GIS-Proposal for Practical Model focusing on Bus Route Planning Support, Hiroshima University Management Research, 2004, pp. 139-150. (in Japanese)

[11] I. Yairi and S. Inoki, GIS Project for Walking Assistance for All Users including Seniors and Disabled People, The Institute of Electronics, Information and Communication Engineers Technical Research Report, 2004, pp. 17-22. (in Japanese)

[12] T. Kasahara and Y. Shimakawa, Review of GIS insertion that estimates foot traffic volume, The Japan Association for College of Technology Journal 13 (2) (2008) 43-48. (in Japanese)

[13] A. S. Niaraki and K. Kim, Ontology based personalized route planning system using a multi-criteria decision making approach, Expert Systems with Applications 36 (2) (2009) 2250-2259.

[14] Kawagoe City, Results of Questionnaire on Traffic in Kawagoe and Ichiban-gai, 2009, p. 23. (in Japanese)

[15] Kawagoe City, Kawagoe City Tourism Questionnaire Report 2009, 2010, p. 26. (in Japanese)

[16] Kawagoe City, Kawagoe City Local Public Transport Comprehensive Coordination Plan, 2010, p. 13. (in Japanese)

[17] H. Ishihara and Y. Izumi, Basic Research in Everyday Spheres, 2006 Urban Centre Research Report, 2006, p. 6. (in Japanese). 